\title{
Peer Review - The Noblest Duty of Every Researcher
}

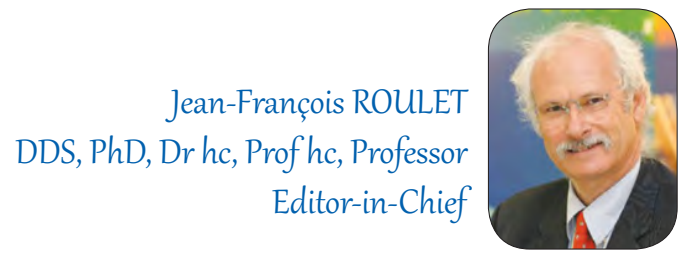

Dear readers,

In the very first editorial for the Stomatology Edu Journal, I have stated the importance of the peer review process. It is designed to guarantee that "Nothing is scientifically shown or proven before it has been published in a scientific journal with a peer review system, so one can critically judge what was done, how it was done and evaluate how solid it is." as Andreas Linde, the editor of the Scandinavian Journal Dental Research has stated.

Have you ever searched ("googled") a topic you are very familiar with on the internet? 1 did this several times and was shocked every time. For instance, if you google "Fluoride" you get 26,00o,ooo hits in 0.43 seconds. You could argue that this is proof that Fluoride is probably the most investigated substance in the world. True. The first hit shown is Fluoride Wikipedia, which presents a neutral description of its chemical properties, occurrence, biologic interactions etc. This is how it should be. However, the second hit is titled "Fluoride - Dangers of Fluoridation" and leads you to www.mercola.com. What you find is a collection of all the fairy tales about Fluoride which are disseminated by an active group of people. We all know from scientifically based literature that these claims are faulty and misleading and that fluoride, regarding its therapeutic width, is safer than table salt or even water. You find Fluoride articles "sort by recent". 1 quote the first eight following headlines: "The lawsuit that could end water fluoridation in the US, Two major league victories in federal court cases to end water fluoridation, Update on the movement against water fluoridation, Chinese herb shows promise against tooth decay, Fluoride - A little bit at the wrong time is devastating, Fluoride: Poison on tap, Maternal fluoride exposure during pregnancy correlates to lower $1 \mathrm{Q}$ in their children, Short Film reveals the lunacy of water fluoridation." Under the last quoted title 1 can read: "What has been hailed as one of the top 10 public health achievements of the zoth century is instead ripe with lies and deception, with absolutely no science to support it. That's why I'm working tirelessly to put an end to this lunacy that's wrecking health."

My question is, how should someone not informed, seeking for knowledge be able to validate these two sources that are equal in the result of the internet search? You see now my point why the peer review process is the noblest duty of every scientist.

It is wonderful and very beneficial to have peer review. The reviewer almost becomes a member of the author team, although anonymous, and contributes to the quality of the paper. However, peer reviewing has its problems: Editors worldwide notice that it gets more and more difficult to find colleagues who are willing to perform peer reviews. We editors sometimes send out 5-6 requests hoping to get at least two answers. 1 think this is very sad and damaging to the idea of high-quality publications. Furthermore, 1 think that a crew of professional reviewers is not the answer, because to do a good review one must be deeply involved in the mater that has to be reviewed. 
Therefore, dear colleagues say "YES", when you are asked to do a peer review! 1 know, we are all very busy, busier than ever. Furthermore, to perform a good review is time-consuming. However, think about it: If there are no reviewers anymore there will be no peer review as well. Where would you then publish your papers, with the mandatory request for your career that they must be peer reviewed?

J-FRoulet

Editor-in-Chief

References

Roulet]-F. Why Peer Review? Stoma Edu]. 2014;1(1):6.

DOI: 10.25241/stomaeduj.2018.5(2).edit.1 